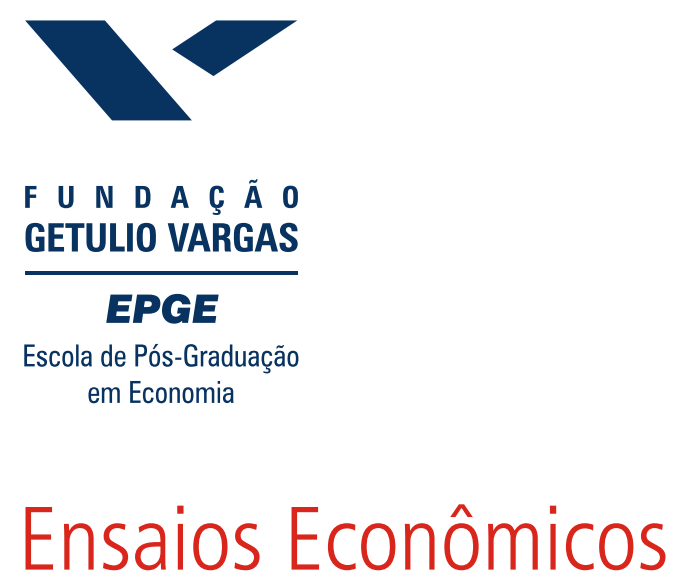

$$
\begin{aligned}
& \text { Escola de } \\
& \text { Pós Graduação } \\
& \text { em Economia } \\
& \text { da Fundação } \\
& \text { Getulio Vargas }
\end{aligned}
$$

The Effects of Longevity and Distortions on Education and Retirement

Pedro Cavalcanti Ferreira, Samuel de Abreu Pessôa Junho de 2005 
Os artigos publicados são de inteira responsabilidade de seus autores. As opiniões neles emitidas não exprimem, necessariamente, o ponto de vista da Fundação Getulio Vargas. 


\title{
The Effects of Longevity and Distortions on Education and Retirement*
}

\author{
Pedro Cavalcanti Ferreira ${ }^{\dagger} \quad$ Samuel de Abreu Pessôa
}

\begin{abstract}
This article studies the impact of longevity and taxation on life-cycle decisions and long-run income. Individuals allocate optimally their total lifetime between education, working and retirement. They also decide at each moment how much to save or consume out of their income, and after entering the labor market how to divide their time between labor and leisure. The model incorporates experience-earnings profiles and the return-to-education function that follows evidence from the labor literature. In this setup, increases in longevity raises the investment in education - time in school and retirement. The model is calibrated to the U.S. and is able to reproduce observed schooling levels and the increase in retirement, as the evidence shows. Simulations show that a country equal to the U.S. but with $20 \%$ smaller longevity will be $25 \%$ poorer. In this economy, labor taxes have a strong impact on the per capita income, as it decreases labor effort, time at school and retirement age, in addition to the general equilibrium impact on physical capital. We conclude that life-cycle effects are relevant in analyzing the aggregate outcome of taxation.
\end{abstract}

\footnotetext{
${ }^{*}$ We gratefully acknowledge the comments and suggestions of João Issler, Marcos B. Lisboa, several seminar participants around the world and two anonymous referees. All remaining errors are ours. The authors also acknowledge the financial support of CNPq-Brazil, PRONEX and Capes/Cofecub.

${ }^{\dagger}$ Both authors are from the Graduate School of Economics ( EPGE ), Fundação Getulio Vargas, Praia de Botafogo 190, 1125, Rio de Janeiro, RJ, 22253-900, Brazil. Email addresses of the authors are, respectively, ferreira@fgv.br and pessoa@fgv.br
} 


\section{Introduction}

One of the most impressive facts of the twentieth century is the large increase of educational attainment of the adult population. In 1990, the median schooling of a male aged 25 years in the U.S., according to estimations in Gustavus and Nam (1964) based on Census Data, was 6.8 years. By 2000 it had jumped to more than 12 years (Jones (2002)).

Even more dramatic is the rise of longevity in the same period. At the beginning of last century, life expectancy at birth was, on average, less than 48 years, according to the

National Vital Statistics Reports (2002). One hundred years later it was estimated to be 77 years. Although most gains were related to reduction of child mortality, the increase of adult longevity in the same period is very significant. The life expectancy of a man aged 20 years in 1900 was 42.8 years, but in 2000 a man of the same age was expected to die 57.8 years later, a 15-years variation.

These two facts may not be unrelated. Greater longevity allows for extension of the population working life and, consequently, an increase in the present value of the flow of wages of a given investment in education. Higher returns to education in turn induce individuals to stay longer in school, increasing the average human capital of the population, with a potential effect on long-run income.

At the same time, the number of years individuals spend in retirement increased continuously in the previous century. Lee(2001) calculates that the expected period of retirement increased from 2.6 years for the cohort born in 1880 to 13.1 years to the cohort born in 1930 . Moreover, labor-force participation for men aged 65 and over went from 58\% in 1930 to only $16 \%$ by 1985 (Kalemli-Ozcan and Weil (2004)). In principle, this fact does not contradict the link between life expectancy and schooling, as working and retirement lives could have increased with the longevity. However, Gendell and Siegel (1992) estimate that age at final retirement has fallen by 4 to 5 years since 1950, for both men and women. Median age of retirement for men fell from 66.9 years in 1950-55 to 62.6 in 1985-1990. More years at school and younger retirement age can only mean shorter career length, something at odds with the idea that longevity influences schooling because it increases the period one can enjoy the return to education investment.

In this paper we develop a model that reconciles the above facts. Individuals allocate their total lifetime between education, working and retirement. They also decide at each moment how to divide their time between labor and leisure and how much to save or consume 
out of their income. The labor/leisure choice is key for the retirement decision. In order to explain, however, why people stop working completely at a certain age and do not spread leisure evenly, the model incorporates experience-earnings profiles that mimics the evidence from the labor literature (e.g., Heckman, Lochner and Todd (2003), among others). At a given moment of a worker's life, productivity growth slows down or decreases, so that labor supply falls continuously up to a point when the marginal gain of working is smaller than that of leisure and then individuals leave the labor market for good.

In this model, increases in longevity raises investment in education and retirement life, everything else constant. We are then able to explain in an unified framework these two life-cycle observations. The model is simulated after being calibrated to U.S. observations. We reproduced qualitatively and quantitatively the main facts. Moreover, if learning technology is faster today than in the past-something that one may infer from estimations across different decades - in addition to rising retirement life we obtain that retirement age falls with longevity. This is so because agents prefer to work more intensively when they are young and more productive, increase savings, and retire earlier. Another result is that when we use the population growth rates of the beginning and end of the century, we reproduce schooling levels observed at these two points in time.

The theory we propose is also convenient to study development effects of public taxation. We introduce in the economy distortions to human and physical capital investment as well as labor taxation. The many decision dimensions and two sectors of production ("goods" and "education") constitute a rich general equilibrium environment to explore the transmission mechanisms of public policy. For instance, labor taxation distorts the work-leisure decision, but also the education choice - as it impacts its return - and retirement, because it changes the opportunity cost of not working. The last two channels are not usually present in this type of analysis. Consequently, by just focusing on the first dimension, and on its indirect impact on physical capital (also present here), there is a tendency to underestimate the impact of labor taxation. As a matter of fact, we show that in the long-run labor taxation may be more detrimental to per capita income levels than capital and human capital taxation, a result that contrasts with Lucas(1990), among many.

We believe that this article extends and improves the previous literature in many respects. First, as said before, we bring together in a single model two strands of the literature that study separately, in the context of development and growth, the impact of longevity on schooling and retirement. In Soares (2003), Enrlich and Lui (1991) Khakemi-Ozacan, Ryder 
and Weil(2000) and Boucekkine, de la Croix and Licandro(2002) longer lives become by definition longer career span and retirement is non-existent. That may be a good hypothesis for the seventeenth and eighteenth century Europe, the period examined by Boucekkine, de la Croix and Licandro(2003), but certainly not for the U.S. after 1950. Kabosky(2003) allows working life to vary with longevity, but he treats career spans exogenously and calibrates it to the U.S. observed path ${ }^{1}$.

As opposed to some of the studies above, in our framework schooling and human capital have level effects on per capita income, not permanent growth effects. The evidence in Bils and Klenow (2000) and Krueger and Lindhal (2000) does not favor the latter, nor externality due to human capital. Moreover, the model generates rising schooling as a steady-state result, in contrast to Jones(2002).

A second literature that relates to ours investigates the links between longevity and retirement. Khakemi-Ozacan and Weil(2004) show that exogenous decreases in the probability of death, which allows people to better plan saving for old age, generates longer retirement from life. This is a different explanation from ours, which relies on the income effect due to the longevity-schooling channel and declining productivity, on the individual level, at old age. Their model also incorporates labor-leisure choices, but there is no education decision. As our taxation exercises show, these two dimensions are closely linked. In a sense, our explanation also relates to that in Graebner(1980), says that technological change leads to retirement because the learning of old people is slower, making then obsolete in periods of faster innovation. In our model there are different learning rates for young and old people, the latter being smaller. However, one also needs longevity effects to explain higher retirement life in the dimension observed in the past. Not to mention, of course, schooling expansion.

Finally, we also study the long-run impact of human capital, physical capital and labor taxation. In our model, as in Trosten(1993) and Bills and Klenow(2002), foregone wages are not the only cost of human-capital investment, there are also tuition costs. We show that in this framework, labor taxes and taxes on tuition have significant impact on the schooling decision. As opposed to Stokey and Rebelo (1995) and Hendricks (1999) they do not have

\footnotetext{
${ }^{1}$ Also related to our article are Bils and Klenow (2000) and Mateus-Planas (2001), which also use a Mincerian formulation of schooling with a life-cycle decision regarding education. Neither formulation considers a second sector that provides educational services as we do; they have no taxation and do not explore fully the general equilibrium impact of life-cycle features of human-capital investment.
} 
growth effect, only level effect. This is similar to Trosten(1993)who nevetheless, ignores life-cycle effects as he uses a dynastic framework. It also contrasts with Lucas(1990), who suggests that life-cycle effects are not relevant in analyzing the aggregate effects of taxation. Results in this article show that they are qualitatively and quantitatively important.

The article is organized as follows. In the next section we present the model and briefly discuss the hypothesis of exogenous life expectancy. Section 3 discusses calibration and measurement issues. Results concerning the link between education and retirement are presented in Section 4, while sensitivity analysis, focusing mostly on distortions, are presented in Section 5. Section 6 concludes.

\section{The Model}

The model assumes finite lifetime with endogenous decision of education, labor effort (leisure), retirement and savings. Human capital depends on the education acquired while in school and on-the-job learning, which is exogenous. Individuals choose how long to go to school so as to maximize the present value of lifetime earnings. The return to human-capital investment depends on, longevity, taxes and the experience profile, among other variables. Retirement is also influenced by the experience profile: if productivity is falling too fast at some point in life, it may be better to stay in home and enjoy leisure. As for the production side of this economy, there are two sectors - the "good" and "educational" sectors - both of which use physical capital and effective labor according to homogenous production functions. Government school-tuition taxes, labor and physical-capital incomes. School tuition is equivalent to a direct cost of schooling and is not proportional to wages. Tax revenues are transferred lump-sum to individuals.

Although most of the related literature assumes, as we do, exogeneity of life expectancy, this is of course a major issue. Preston (1975) shows that economic advances in the last century in developed and less developed countries was not a major factor in the increase of life expectancy. Simple sanitation and medical discoveries, for instance, that can be copied at almost no cost, were more relevant. He constructs a scatter diagram for different nations, showing that the relationship between life expectancy at birth and national income per capita shifted upwards during the twentieth century: a country with income per capita in 1960 between $\$ 100$ and $\$ 500$ had 10-12 more years of life expectancy than another country 
with a similar income level in 1930. Soares (2003) adds 1990 data to Preston's figure and also concludes that for constant levels of income, life expectancy has been rising. He shows that a nation with per capita income of $\$ 5000$ in 1995 had a life expectancy roughly $10 \%$ higher than a country with the same per capita income in 1960

Preston(1975) estimates that factors exogenous to a country's level of economic development account for 75-90 per cent of the growth in life expectancy for the world as a whole between the 1930s and the 1960s and that these exogenous factors had a major effect on mortality trends in more developed as well as in less developed countries. France and Austria gained almost 13.7 years of life expectancy in the period, only 0.4 years above Indonesia's gain and less than 3 years above that of the Philippines Lee(1980), Kirk (1996) and Preston(1977), among others, also confirm in different contexts the exogeneity of life expectancy, which is then assumed in the present model.

This section is organized as follows: in the next subsection we study the production side of the economy and in the following individual choices. We then study demography and the government and present the equilibrium of the model in the last subsection.

\section{$2.1 \quad$ Firms}

There are two sectors in this economy, one that produces consumption and investment goods and other that produces educational services; both use effective labor and physical capital as inputs. Let output $Y_{1}$ in the Goods Sector be a function of physical-capital services $K_{1}$ and skilled labor $H_{1}$ according to:

$$
Y_{1}=A_{1} K_{1}^{\alpha_{1}} H_{1}^{1-\alpha_{1}}
$$

where $A_{1}$ is the total-factor productivity of the goods sector. Skilled labor is given by:

$$
H_{1}=L_{1} e^{\phi\left(T_{S}\right)}
$$

where $L_{1}$ is raw labor. According to the equation above, the productivity of a worker with $T_{S}$ years of schooling is $e^{\phi\left(T_{S}\right)}$ greater than that of a worker of the same cohort with no education at all. The function $\phi\left(T_{S}\right)$ is assumed to be increasing and to exhibit diminishing returns, and $\phi^{\prime}\left(T_{S}\right) e^{\phi\left(T_{S}\right)}$ gives the increase in effective labor input from one extra year of schooling. Likewise, output in the educational sector is given by:

$$
Y_{2}=A_{2} K_{2}^{\alpha_{2}}\left(L_{2} e^{\phi\left(T_{S}\right)}\right)^{1-\alpha_{2}},
$$


Let $p_{i}$ be the price of the $i$-th sector good. Profit maximization of the firm gives

$$
R_{i}=p_{i} \alpha_{i} A_{i} k_{i}^{\alpha_{i}-1} \text { and } w_{i}=p_{i}\left(1-\alpha_{i}\right) A_{i} k_{i}^{\alpha_{i}}
$$

where $R_{i}$ is the rental price of capital, $w_{i}$ is the wage rate (of raw labor without on-the-job experience), and

$$
k_{i} \equiv \frac{K_{i}}{L_{i} e^{\phi\left(T_{S}\right)}},
$$

is the $i$-th sector employment of capital in efficiency units.

In this economy there is free mobility of factors across sectors, so that price factors are the same in both sectors. Considering the good 1 as the numeraire, it follows that:

$$
R \equiv R_{1}=\alpha_{1} A_{1} k_{1}^{\alpha_{1}-1}=p \alpha_{2} A_{2} k_{2}^{\alpha_{2}-1}=R_{2}
$$

and

$$
w \equiv w_{1}=\left(1-\alpha_{1}\right) A_{1} k_{1}^{\alpha_{1}}=p\left(1-\alpha_{2}\right) A_{2} k_{2}^{\alpha_{2}}=w_{2},
$$

where $p$ is the relative price of educational services in units of goods. The factor-allocation problem is standard and is presented in the appendix. The production side of this economy is essentially a traditional two-sector, two-factor model, and from its solution we obtain the offer function of each sector, given $p$ and $k$, the per-worker capital stock in efficiency units:

$$
y_{i}(p, k)=A_{i} l e^{\phi\left(T_{\mathrm{S}}\right)} l_{i}(p, k)\left[k_{i}(p)\right]^{\alpha_{i}}, \quad i=1,2
$$

where $y_{i}$ is the per capita supply function of sector $i, l$ is the total flow of raw labor services per capita and $l_{i}$ is the share of labor in sector $i$.

The two-sector framework is a convenient and realistic way of modeling the direct cost of educational services. Moreover, without an education sector of production, taxes on labor and on the direct cost of schooling would be equivalent.

\subsection{Household}

Individuals live for $T$ years and retire after $T_{R}$ years. Retirement is not mandatory but is chosen optimally. In the first part of the life cycle, ("youth", $T_{Y}$ ), individuals first stay at home for $T_{C}$ years and then go to school for $T_{S}$ years. Once they leave school, they cannot return. They then join the labor market, working for $T_{W}$ years. Active life has two sub-periods: $T_{\mathrm{W} 1}$, when wages increase with on-the-job learning - which is exogenous in the 
model - and $T_{\mathrm{W} 2}$, when they decrease (or increase at a slower pace). This latter hypothesis follows ample evidence from the labor literature (e.g., Heckman, J., L. Lochner e P. Todd, 2003) of a hump-shaped (log) earnings-experience profile throughout the worker's life-cycle.

At each instant of time the household decides how much to consume or save and how much work effort to supply. A once-for-all decision is also made on how much education to buy, which is equivalent in the model to deciding the optimal period of time $T_{\mathrm{S}}$ of staying in school. The utility function of an individual is:

$$
\int_{0}^{T} e^{-\rho a}[\beta \ln c(a)+(1-\beta) \ln (1-l(a))] \mathrm{d} a,
$$

where $c(a)$ and $l(a)$ are respectively the consumption and the labor effort of an age $a$ individual, while $\rho$ is the discount rate. We already normalized the time endowment to one.

Individuals have three sources of income - wages from labor services, rents from capital, and public transfer - which are used to pay for school tuition and consumption goods. In intertemporal format their budget constraint is given by:

$$
\begin{aligned}
& \int_{T_{\mathrm{Y}}}^{T_{\mathrm{Y}}+T_{\mathrm{W}}} e^{-r a}\left(1-\tau_{\mathrm{L}}\right) w\left(T_{s}, a, x\right) l(a) \mathrm{d} a+\int_{0}^{T} e^{-r a} \chi \mathrm{d} a \\
= & \int_{0}^{T} e^{-r a} c(a) \mathrm{d} a+\left(1+\tau_{\mathrm{H}}\right) \int_{T_{\mathrm{C}}}^{T_{\mathrm{Y}}} e^{-r a} \eta p \mathrm{~d} a,
\end{aligned}
$$

where $r$ is the interest rate, $w\left(T_{s}, a, x\right)$ is the wage of age- $a$ worker with $T_{s}$ years of education and experience $x, \tau_{\mathrm{L}}$ is a tax (or subsidy) rate on wages and $\chi$ are government transfers. The last expression on the right hand side is tuition costs, where $\tau_{\mathrm{H}}$ is a tax (or subsidy) rate on education purchases and $\eta$ the amount of education services that the student has to buy in order to be in school ${ }^{2}$. The above expression simply says that the net present value of wages and government transfers should be equal to the net present value of consumption and tuition costs.

\footnotetext{
${ }^{2}$ We are assuming indivisibility in the human- capital accumulation process. In order to increase his education level, an individual has to buy $\eta$ units of educational services but cannot buy fractions of it.
} 


\subsubsection{Labor Supply and Retirement Decisions}

The function $w\left(T_{s}, a, x\right)$ follows closely the labor literature:

$$
w\left(T_{s}, a, x\right)=w e^{\phi\left(T_{S}\right)} x(a),
$$

where $x(a)$ is the "experience function" that gives the increase in productivity while at work.

There is ample evidence that for a given level of education, workers' experience-earnings profiles are such that wages increase initially but later in life decrease with age. Heckman, Lochner and Todd (2003), for instance, using Census data from 1940 to 1990, for white and black males, show that in most cases, regarders of the educational level, mean log annual wage and salary income is a parabolic function of experience. The variation of productivity due to on-the-job learning $(x)$ will be modeled as:

$$
x(a)=\left\{\begin{array}{c}
e^{\gamma\left(a-T_{\mathrm{Y}}\right)} \text { if } T_{\mathrm{Y}} \leq a \leq T_{\mathrm{Y}}+T_{\mathrm{W} 1} \\
e^{\gamma T_{\mathrm{W} 1}-\xi\left(a-\left(T_{\mathrm{Y}}+T_{\mathrm{W} 1}\right)\right)} \text { if } a \geq T_{\mathrm{Y}}+T_{\mathrm{W} 1},
\end{array}\right.
$$

According to the above function, from the moment a worker enters the job market $\left(T_{Y}\right)$ to some turning point $T_{W 1}$ labor productivity due to experience increases at a constant rate $\gamma$. After this point, it falls at a rate $\xi$ until the worker retires or dies ${ }^{3}$.

Simple calculation gives us the first-order condition for the labor supply choice at each moment of time:

$$
l(a)=1-\frac{1-\beta}{\mu} \frac{e^{(r-\rho) a}}{\left(1-\tau_{\mathrm{L}}\right) w e^{\phi\left(T_{\mathrm{S}}\right)} x(a)},
$$

where $\mu$ is the Lagrange multiplier associated to restriction (4).

In this economy retirement is endogenous. Given the decrease of productivity at old age, there is a moment when the marginal gain of staying longer in the job market and being able to afford more consumption goods becomes smaller then the marginal gain from leaving the job market and using the entire time endowment for leisure. At this point the individual leaves the job market, so that retirement occurs when labor supply is zero:

$$
\frac{1-\beta}{\mu}=\left(1-\tau_{\mathrm{L}}\right) w e^{\phi\left(T_{\mathrm{S}}\right)} e^{-(r-\rho)\left(T_{\mathrm{Y}}+T_{\mathrm{W}}\right)} x\left(T_{\mathrm{Y}}+T_{\mathrm{W}}\right) .
$$

\footnotetext{
${ }^{3}$ Function $x(a)$ is more commonly represented in the literature by $x(a)=e^{\gamma\left(a-T_{\mathrm{Y}}\right)+\xi\left(a-T_{\mathrm{Y}}\right)^{2}}$, with $\gamma>0$ and $\xi<0$. However, in the present context the computational procedure implied by this functional form would be extremely cumbersome, so we approximated it by (5) for simplicity.
} 
In the relevant situation when $T_{\mathrm{Y}}+T_{\mathrm{W}}>T_{\mathrm{Y}}+T_{\mathrm{W} 1}$ we have, after applying (5) in the expression above, that:

$$
e^{-\rho\left(T_{\mathrm{Y}}+T_{\mathrm{W}}\right)} \frac{1-\beta}{\mu}=e^{-r\left(T_{\mathrm{Y}}+T_{\mathrm{W}}\right)}\left(1-\tau_{\mathrm{L}}\right) w e^{\phi\left(T_{\mathrm{S}}\right)} e^{\gamma T_{\mathrm{W} 1}-\xi T_{\mathrm{W} 2}} .
$$

The equation above equates the present value leisure, at retirement time, to the net present value of wages.

\subsubsection{Consumption Decision}

In their consumption decision, individuals maximize (3) subject to (4). Solving for consumption, we obtain the individual's consumption profile:

$$
c(a)=c(0) e^{(r-\rho) a} .
$$

In order to find consumption at each moment of time we need to know the initial consumption. After substituting into the budget constraint (equation 4 above) the expressions (8), (5), and (6) it follows that:

$$
\begin{aligned}
& c(0) \frac{1-e^{-\rho T}}{\rho}+\left(1+\tau_{H}\right) p \eta e^{-r T_{\mathrm{C}}} \frac{1-e^{-r T_{\mathrm{S}}}}{r}+e^{-\rho T_{\mathrm{Y}}} \frac{1-\beta}{\mu} \frac{1-e^{-\rho T_{\mathrm{W}}}}{\rho} \\
= & \left(1-\tau_{\mathrm{L}}\right) w e^{\phi\left(T_{\mathrm{S}}\right)} e^{-r T_{\mathrm{Y}}}\left[\frac{1-e^{-(r-\gamma) T_{\mathrm{W} 1}}}{r-\gamma}+e^{-(r-\gamma) T_{\mathrm{W} 1}} \frac{1-e^{-(r+\xi) T_{\mathrm{W} 2}}}{r+\xi}\right]+\chi \frac{1-e^{-r T}}{r},
\end{aligned}
$$

The right-hand term is the individual's total wealth at the time of birth, given by the market value of labor endowment ${ }^{4}$ and government transfers. The household spends his wealth (in the left-hand side) buying goods, education services and leisure, respectively. Note that we have already substituted into the equation above the steady-state equilibrium condition Consumption and education decision are stationary across cohort.

\subsubsection{Education Decision}

In this economy, the education decision is equivalent to choosing the optimal time to leave school. In the beginning of their lives, individuals pick the optimal quantity of education in

\footnotetext{
${ }^{4}$ The market value of labor endowment has two components, as seen inside the brackets. The first term corresponds to the period in which experiences increases at a rate $\gamma$ and the second to the period in which it falls at a rate $\zeta$
} 
order to maximize the present value of wages net of tuition cost, as given in (4):

$$
\max _{T_{\mathrm{S}}}\left[\int_{T_{\mathrm{C}}+T_{\mathrm{S}}}^{T_{\mathrm{C}}+T_{\mathrm{S}}+T_{\mathrm{W}}} e^{-r a}\left(1-\tau_{\mathrm{L}}\right) w e^{\phi\left(T_{\mathrm{S}}\right)} x(a) l(a) \mathrm{d} a-\left(1+\tau_{\mathrm{H}}\right) \int_{T_{\mathrm{C}}}^{T_{\mathrm{C}}+T_{\mathrm{S}}} e^{-r a} \eta p \mathrm{~d} a\right] .
$$

In making this decision (for a fixed retirement life), individuals consider that the longer they stay in school, the shorter their productive life $\left(T_{\mathrm{W}}\right)$, given that life span is exogenous. Moreover, in addition to the foregone wages, there is the direct cost of school tuition. We assume that the age at which labor productivity peaks, $T_{\mathrm{S}}+T_{\mathrm{W} 1}$, is exogenous and independent of education; any additional year at school reduces the productive life at the first sub-period ${ }^{5}$.

In this case, the first-order condition for the educational choice follows ${ }^{6}$ :

$$
\begin{aligned}
& \left(\phi^{\prime}\left(T_{\mathrm{S}}\right)-\gamma\right)\left\{\left(1-\tau_{\mathrm{L}}\right) w e^{\phi\left(T_{\mathrm{S}}\right)}\left[\frac{1-e^{-(r-\gamma) T_{\mathrm{W} 1}}}{r-\gamma}+e^{-(r-\gamma) T_{\mathrm{W} 1}} \frac{1-e^{-(r+\xi) T_{\mathrm{W} 2}}}{r+\xi}\right]-\right. \\
& \left.\frac{1-\beta}{\mu} e^{(r-\rho) T_{\mathrm{Y}}} \frac{1-e^{-\rho T_{\mathrm{W}}}}{\rho}\right\}=\left(1-\tau_{\mathrm{L}}\right) w e^{\phi\left(T_{\mathrm{S}}\right)}-\frac{1-\beta}{\mu} e^{(r-\rho) T_{\mathrm{Y}}}+\left(1+\tau_{\mathrm{H}}\right) \eta p .
\end{aligned}
$$

The expression above equates the marginal contribution of schooling to lifetime earnings, on the left-hand side, to its marginal cost, on the right-hand side. The latter is the opportunity cost (net of leisure) of not working (i.e., the wages lost) plus the tuition cost at the time of stopping. The former is the impact on the present value of time endowment (net of leisure) of staying in school one additional unit of time - which implies higher wages in the future due to more schooling, but a loss of experience ${ }^{7}$.

Note that dividing both sides of equation (9) by $1+\tau_{\mathrm{H}}$ one can see (recall from (7) that $(1-\beta) / \mu$ is proportional to $\left.w e^{\phi\left(T_{\mathrm{S}}\right)}\right)$ that tax on tuition, in the context of the schooling decision, is equivalent to direct taxation on labor earnings. Note also that were it not for the tuition term, human capital taxation or taxes on wages would have no impact at all, as a

\footnotetext{
${ }^{5}$ This hypothesis seems to us more sensible than assuming that $T_{W 1}$ alone is exogenous. Experienceearning profiles in Heckman, Lochner and Todd (2003) of different schooling levels peak at approximately the same age, especially in the case of white males.

${ }^{6}$ Actually, (9) is the first-order condition with respect to education after, for the sake of simplification we substituted in (7) using also the fact that at retirement time, wages (net of leisure) are zero.

${ }^{7}$ It may be helpful, in order to get more intuition, to think of a model with no labor choice and no experience gain. In this case equation (9) simplifies to: $w e^{\phi\left(T_{S}\right)} \phi^{\prime}\left(T_{S}\right) \frac{1-e^{-r T_{W}}}{r}=w e^{\phi\left(T_{S}\right)}+\left(1+\tau_{H}\right) \eta q$, which equates the present value of staying in school one additional unit of time (the left-hand side) to the opportunity cost of not working plus the tuition cost at the time of heaving school (the right-hand side).
} 
tax term $\left(1+\tau_{\mathrm{H}}\right)\left(1-\tau_{\mathrm{L}}\right)$ would divide both sides of the above expression (all components being proportional to $\left.w e^{\phi\left(T_{\mathrm{S}}\right)}\right)$ and, consequently, be eliminated.

\subsection{Demography}

At each instant of time a cohort of size $m e^{n t}$ is born, where $m \equiv n /\left(1-e^{-n T}\right)$, so that total population is given by

$$
\int_{t-T}^{t} m e^{n s} \mathrm{~d} s=e^{n t} .
$$

Within a cohort, all individuals are identical. Let $N(a)$ be the share of the $a$-cohort.on the total population. At time $t$ the $a$-cohort is the cohort born in $s=t-a$. We have:

$$
N(a)=\frac{m e^{n s}}{e^{n t}}=m e^{-n a} .
$$

Let $N_{\mathrm{C}}, N_{\mathrm{S}}, N_{\mathrm{W}}$, and $N_{\mathrm{R}}$ be, respectively, the population of children, students, workers, and retirees as a share of total population. We have:

$$
N_{\mathrm{S}}=\int_{T_{\mathrm{C}}}^{T_{\mathrm{C}}+T_{\mathrm{S}}} m e^{-n a} \mathrm{~d} a=e^{-n T_{\mathrm{C}}} \frac{1-e^{-n T_{\mathrm{S}}}}{1-e^{-n T}} .
$$

Likewise, we get that:

$$
N_{\mathrm{C}}=\frac{1-e^{-n T_{\mathrm{C}}}}{1-e^{-n T}}, N_{\mathrm{W}}=e^{-n T_{\mathrm{Y}}} \frac{1-e^{-n T_{\mathrm{W}}}}{1-e^{-n T}} \text { and } N_{\mathrm{R}}=e^{-n\left(T-T_{\mathrm{Y}}\right)} \frac{1-e^{-n T_{\mathrm{R}}}}{1-e^{-n T}} .
$$

\subsubsection{Total Labor Supply}

In order to characterize the supply functions given by (2) we have to determine $l$, the total flow of raw labor services per capita. As individuals work from age $T_{\mathrm{Y}}$ to age $T_{\mathrm{Y}}+T_{\mathrm{W}}$, we have:

$$
l=\int_{T_{\mathrm{Y}}}^{T_{\mathrm{Y}}+T_{\mathrm{W}}} N(a) l(a) x(a) \mathrm{d} a .
$$

After substituting the experience profile (5), labor supply (6), the expression for $N(a)(10)$ and (7) ,and solving the integral, we obtain:

$$
\begin{gathered}
l=m e^{-n\left(T_{\mathrm{Y}}+T_{W 1}\right)} e^{\gamma T_{\mathrm{W} 1}} \times \\
\left\{\frac{1-e^{-(\gamma-n) T_{\mathrm{W} 1}}}{\gamma-n}+e^{-(n+\xi) T_{\mathrm{W} 2}}\left[\frac{e^{(n+\xi) T_{\mathrm{W} 2}}-1}{n+\xi}-\frac{1-e^{-(r-(\rho+n)) T_{\mathrm{W}}}}{r-(\rho+n)}\right]\right\} .
\end{gathered}
$$




\subsection{Government Restriction}

At a point in time, government revenue is given by the sum of taxation of educational services, on labor services and capital income. The first component is given by:

$$
\tau_{\mathrm{H}} p \int_{T_{\mathrm{C}}}^{T_{\mathrm{Y}}} N(a) \eta \mathrm{d} a=\tau_{\mathrm{H}} p m \eta e^{-n T_{\mathrm{C}}} \frac{1-e^{-n T_{\mathrm{S}}}}{n},
$$

the second component by

$$
\tau_{\mathrm{L}} \int_{T_{\mathrm{Y}}}^{T_{\mathrm{Y}}+T_{\mathrm{W}}} N(a) w e^{\phi\left(T_{\mathrm{S}}\right)} x(a) l(a) \mathrm{d} a,
$$

$\nabla$ and the third component by $\tau_{\mathrm{K}} R K$. Consequently, the per capita government transfer is the sum of these 3 terms divided by $e^{n t}$ :

$$
\chi=\tau_{\mathrm{H}} p \eta m e^{-n T_{\mathrm{C}}} \frac{1-e^{-n T_{\mathrm{S}}}}{n e^{n t}}+\frac{\tau_{\mathrm{K}} R K}{e^{n t}}+\frac{\tau_{\mathrm{L}}}{e^{n t}} \int_{T_{\mathrm{Y}}}^{T_{\mathrm{Y}}+T_{\mathrm{W}}} N(a) w e^{\phi\left(T_{\mathrm{S}}\right)} x(a) l(a) \mathrm{d} a,
$$

after solving the integral in the last term on the right hand side.

\subsection{Equilibrium}

Before presenting the equilibrium conditions of this economy, we need to derive an expression for aggregate consumption, which is necessary for the equilibrium of the market for goods. This is done by adding the individual consumption over cohorts:

$$
c \equiv \frac{C(t)}{e^{n t}}=\int_{0}^{T} N(a) c(a) \mathrm{d} a .
$$

If we substitute equation (8) into this last equation we obtain

$$
c=c(0) m \frac{e^{(r-(\rho+n)) T}-1}{r-(\rho+n)}
$$

The final expression is trivially obtained by plugging the expression for initial consumption in the above expression.

We can now describe the steady-state equilibrium of this economy, which is given by the following equations: 
- The equilibrium in the market for educational services is:

$$
y_{2}(p, k)=\eta m e^{-n T_{\mathrm{C}}} \frac{1-e^{-n T_{\mathrm{S}}}}{n} .
$$

- The equilibrium in the assets market:

$$
r=\left(1-\tau_{\mathrm{K}}\right) R-\delta=\left(1-\tau_{\mathrm{K}}\right) \alpha_{1} A_{1} k_{1}^{\alpha_{1}-1}-\delta,
$$

- The goods-market equilibrium is:

$$
y_{1}(p, k)=c+(\delta+n) \frac{K}{e^{n t}},
$$

where $c$ is given optimally by equation (13), after the expressions for initial consumption and for government transfers, (12), is plugged in.

- The equilibrium condition with respect to the educational choice, which is given by (9) after using equation (7) to eliminate $(1-\beta) / \mu$.

Note that the equilibrium in the labor and capital markets is implicit in the supply functions $y_{1}(p, k)$ and $y_{2}(p, k)$.

\section{Quantitative Methodology}

\subsection{Calibration}

The model is calibrated to the U.S. in the recent past, assuming the country is in a steadystate equilibrium. Parameters of interest can be separated into two groups. In the first group they are considered as observables while in the second parameters are obtained - measured - using the restrictions imposed by the data on the equilibrium solution of the model. We start presenting observable variables, and in this case we follow the standard procedure of employing data from the U.S. Census, National Account and similar sources. In some cases independent estimations were used.

The capital shares $\alpha_{1}$ and $\alpha_{2}$ were set equal to 0.4 and 0.05 , respectively, and were calculated using U.S. time series data from the National Income and Product Accounts (NIPA). The share of total labor force in the educational sector, $l_{2}$, also obtained from 
the NIPA, is the average from 1987-1997 of the ratio of Full-Time Equivalent Employees in Educational Services to the Total Full-Time Equivalent Employees and was found to be 0.077. The value of $i$, set to 0.2 , was also obtained in the NIPA for the post-1960 period and so was the value of the capital-output ratio, $\kappa$, which will be useful later for the calibration of $k$ and $\delta$. We normalized income per capita, $y$, to one, without loss of generality.

Life expectancy $T$ was set to 77 , which is the value reported in the National Vital Statistics Reports (2002) for 2000. The growth rate of the population is such that $n=\ln (1,013)$, where $1.3 \%$ is the annual population growth rate since 1900, obtained from the U.S. Census. The interest rate was set to $r=\ln (1.05)$.

The variable $T_{S}$ corresponds to data on years of schooling attained by the working-age population (25 years old and over). It was calculated from Census data and set to 13 . In this case we followed the procedure in Jones (2002), simply extending his series until 2000, as it ended in 1993.

The function $\phi\left(T_{S}\right)$ is taken from Bils and Klenow (2000):

$$
\phi\left(T_{S}\right)=\frac{\theta}{1-\psi} T_{S}^{1-\psi}
$$

We follow their estimation and use $\psi=0.58$ and $\theta=0.32$. Hence, instead of the more usual linear return to education assumed in most of the literature, we posit diminishing returns because this seems to be the case when comparing micro estimates across countries (e.g., Psacharopoulos (1994)) and because the linear specification was rejected by the econometric tests in Bils and Klenow(2000).

$T_{\mathrm{W} 1}, \gamma$ and $\xi$ were obtained from Heckman, J., L. Lochner e P. Todd, $(2003)^{8}$. These authors use non-parametric techniques to estimate experience-earnings profiles using Census data. As we assumed linear growth (and linear decrease, after $T_{W 1}$ ), in order to find $\gamma$ we adjusted to their estimated dummies a straight line until the peak $T_{W 1}$. We follow a similar procedure to find $\xi$. This is of course an approximation, but it is necessary to render the model treatable. In the benchmark calibration, $\gamma$ was set equal to $1.25 \%$ and $\xi$ to $1 \%$.

An important piece of statistics that will be important for the calibration procedure is the life-cycle average labor supply of an individual, that by definition is:

$$
\bar{l} \equiv \frac{1}{T-T_{\mathrm{Y}}} \int_{T_{\mathrm{Y}}}^{T_{\mathrm{Y}}+T_{\mathrm{W}}} l(a) \mathrm{d} a .
$$

\footnotetext{
${ }^{8}$ We would like to thank Petra Todd who gave us access to the estimations and data of this article.
} 
After substituting (6) and (7) we obtain:

$$
\bar{l}=\frac{T_{\mathrm{W}}}{T-T_{\mathrm{Y}}}-\frac{1}{T-T_{\mathrm{Y}}}\left[\frac{1-e^{-(r+\xi-\rho) T_{\mathrm{W} 2}}}{r+\xi-\rho}+e^{-(r+\xi-\rho) T_{\mathrm{W} 2}} \frac{1-e^{-(r-(\rho+\gamma)) T_{\mathrm{W} 1}}}{r-(\rho+\gamma)}\right] .
$$

There is evidence in McGrattan and Rogerson (1998) that over the life cycle people work on average 18 hours a week. In order to obtain $\bar{l}$, we divided this value by the total number of weekly hours available to work, which is 24 minus 8 (number of hours for sleeping and physical needs) times seven. We found $\bar{l}=0.161$.

We now explain the solution of the calibration procedure, the methodology used to obtain or measure the parameters not directly observable.

Using $y=1$ and $\kappa=3$, we obtained trivially the steady-state value of per capital , $\frac{K}{e^{n t}}=$ 3. We used $i, \kappa$ and $n$ to find - according to the steady-state expression $(\delta+n) \kappa=i$ - the depreciation rate, which was found to be 0.053. It is also immediate to get $T_{Y}=T_{C}+T_{S}=$ 19 , and consequently $T_{\mathrm{Y}}+T_{\mathrm{W} 1}=51$, the age at which productivity peaks.

Solving (18) we found $T_{\mathrm{W} 2}=16.22$, and solving (11) we got $l=0.15$, the (per capita) total flow of labor services. It then follows from the definition (see appendix) that $\widetilde{k}=2.23$, the value of the per-worker capital stock in efficiency units. Also from the appendix, and the hypothesis of full employment of factors, we have the capital in efficient units per sector, $k_{1}=2.39$ and $k_{2}=0.19$.

Equation (14) solves for the total-factor productivity of the educational sector, $A_{2}=2.37$. Plugging this value and those of $\alpha_{1}$ and $\alpha_{2}$ in equation (21) of the appendix, it solves for $p / A_{1}=0.41$. The definition of $y\left(y_{1}+p y_{2}\right)$, its normalization to one and the formulas of sector supply imply $A_{1}=0.54$ and $p=0.22$.

A similar procedure is used to measure the tax rates: from the equilibrium condition of the asset market, equation (15), it follows that $\tau_{\mathrm{K}}=0.20$. For $\tau_{\mathrm{H}}$ and $\tau_{\mathrm{L}}$ we solved jointly the first-order condition for the education decision - equation (9) - and the goods market equilibrium - equation (16) - and obtained $\tau_{\mathrm{H}}=0.02$ and $\tau_{\mathrm{L}}=0.45$.

The parameter $\rho$ was calibrated so that the life-cycle labor profile reproduced closely those constructed by Rogerson and McGrattan(1998). Charts 2-4 in this article present average hours worked per person by cohorts during their life cycle (extrapolated from United States Census data). Especially in the case of males and total population, these profiles are such that there is a monotonic increase up to a peak, after which the number of hours worked reduces very fast as people get older. By setting $\rho=r-\gamma+\ln (1.0035)$ we obtain a 
labor profile similar to those. By examining (6) and keeping everything constant but $a$, one can see that $l(a)$ increases continuously with age until $a=T_{Y}+T_{W 1}$ and then falls, also continuously ${ }^{9}$.

Finally, from the first order condition of the consumption choice we know that $\frac{\beta}{c(0)}=\mu$ where $\mu$ is the Lagrange multiplier associated to the budget constraint (4). From the firstorder condition for leisure choice we know that, at retirement, $\frac{1-\beta}{\Delta},=\mu$ where

$$
\Delta=\left(1-\tau_{\mathrm{L}}\right) w e^{\phi\left(T_{\mathrm{S}}\right)} e^{-(r-\rho)\left(T_{\mathrm{Y}}+T_{\mathrm{W}}\right)} x\left(T_{\mathrm{Y}}+T_{\mathrm{W}}\right)
$$

Consequently,

$$
\beta=\frac{c(0)}{c(0)+\Delta}=0.20
$$

As opposed to the neoclassical growth model with infinitely-lived individuals, in which $\beta=\bar{l}$, average labor supply here does not coincide with $\beta$. The reason is that now labor supply is not uniform throughout the individual's life cycle and we have to take into account retirement, finite career span and time at school. Moreover, labor effort is not constant during productive life. Note also that, while in infinitely-lived agent models researchers usually find values for beta close to one third, in our case this parameter was found to be considerably smaller.

One way to check if our methodology is reasonably sound is to confront the resulting macro variables or parameters from the model with their observed counterpart. For instance, in the model government participation in GDP is $0.35 \%$, not far from the NIPA figures. Another comforting result is that our measured tax rate on labor is close to that estimated by Prescott(2002), 40\%.

\section{Longevity, Retirement and Education}

The first group of model simulations study the impact of longevity on life-cycle features - time at school and in the labor market. We kept constant TFP, distortions, population growth rate, $\gamma$ and $\zeta$. We also assumed that the productivity peak changes with longevity, so that it will be always the case that $T_{\mathrm{Y}}+T_{\mathrm{W} 1}=(51 / 77) * T$. This is somewhat arbitrary, but there

\footnotetext{
${ }^{9}$ In Rogerson and McGrattan (1998) the positively sloped part is not continuous, it is flatter close to the peak. Our formulation misses this fact, but it would be a hard task to reproduce it especially because this discontinuity changes with cohort, as does the peak. The $\ln (1.0035)$ approximates the mean growth of hours in the first period.
} 
is no clear pattern in the data. For robustness check, we also use alternative parameters and hypotheses. The model is then solved, using different values of $T$, for education, retirement, capital, labor, prices and output.

The figure below displays the relationship between longevity and education.

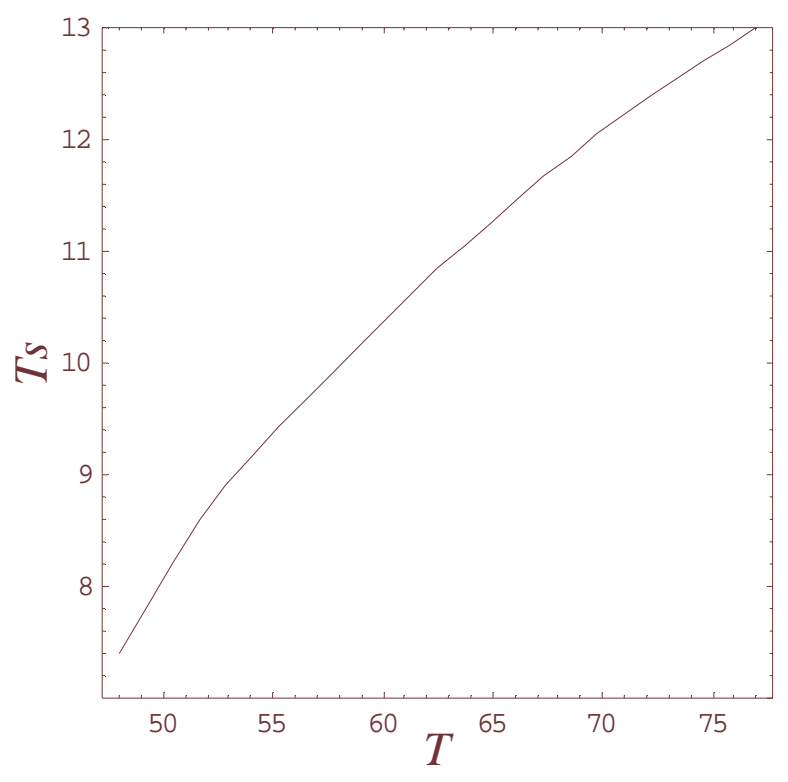

Figure 1: Longevity and Education

The model succeeds in capturing a positive relationship between life expectancy and schooling. We used longevity values in the 48-77 years interval, comprising the variation of life expectancy observed in the last century. Greater longevity allows for the extension of the population's working life and consequently an increase in the present value of the flow of wages of a given investment in education. Higher returns to education in turn induce individuals to stay longer in school. The model simulation found an elasticity of schooling to longevity of $0.74^{10}$.

Note that the model obtains rising educational attainment as a steady-state result. Jones (2002) argues that, from the standpoint of a neoclassical growth model, increases in education

\footnotetext{
${ }^{10}$ Due to the large variation of values we used the arc-elasticity definition.
} 
should generate temporarily high growth rates and long-run level effect, at the same time that the evidence for the U.S. points toward an economy fluctuating around its balanced growth path and no acceleration in the growth rate. This is certainly true in an infinitylived agent model in which the return to schooling by construction does not depend on longevity. In our model, however, increases in the latter raises the return of educational investment so that individuals stay longer in school. Hence, the observed increase in life expectancy during the last century in the US explains, partially at least, the observed path of educational attainment as a steady-state result: to each $T$ corresponds a different $T_{S}$.

Note that although the model simulation is able to reproduce the positive relationship between longevity and education, it tends to overestimate schooling at lower levels of life expectancy. In 1910 the median educational attainment of males aged 25 year and over, according to estimates in Gustavus and Nam (1964), was 6.8 years. Life expectancy in this year, according to the National Vital Statistic Report, was 51.45 years. In this case the model finds $T_{S}=8.5$. When we average with the corresponding figures of education attainment of females, who were largely out of the labor force by this date, we still over-predict schooling by more than one year.

The likely cause of the mismatch is that the simulations are done with parameters calibrated from recent data (e.g., 1990 or 2000) or, as in the case of $n$, using long-run averages. However, experience profile and return to education, for instance, did not remain constant during last century, so that it is not surprising that we could not reproduce the schooling trends perfectly. When we modify the calibration, allowing some parameters to better match the corresponding values of a given period, results tend to improve ${ }^{11}$.

The model also predicts that retirement life increases with longevity, reproducing the evidence for the U.S. When life expectancy is 48 years of life, the figure for males in 1900, the model predicts that people will not stop working before dying. However, using the numbers for 2000, 77 years, the model estimates that retirement life will last almost ten years. The significant expansion of retirement life, as we noted in the introduction, is the

\footnotetext{
${ }^{11}$ For instance, in the first half of the last century average population growth, according to Census data, was $1.40 \%$ a year. Using this value instead of that of the benchmark calibration we obtain $T_{S}=7.05$ in 1910 , very close to the actual figure. Hence, the combined effect of higher longevity and lower population growth explains schooling, so that the model reproduces not only qualitatively the positive relationship between longevity and education, but also quantitatively. Kabosky(2003) has also noted that fertility reduction throughout the twentieth century had a strong effect on the growth of education.
} 
observed evidence for the twentieth century.

In the model, retirement life increases with life expectancy because of an income effect: education rises with longevity and so do wages. As leisure is a normal good, individuals consume more of it. Moreover, given $T$, people retire because in the second period of their working life, as productivity falls, wages decrease and so does the relative cost of leisure, leading people to decrease their work effort. At a certain point, the marginal gain of staying in the job market is smaller than that of dedicating all the time endowment to leisure. In other words, given that people are more productive when young and mature, they rather work harder during this part of their life, save for retirement, and then stop working completely later in life when productivity is falling. This difference in productivity is exactly the reason households do not spread leisure evenly throughout their life, as the return to work is lower at old age.

Figure 2 below presents labor profiles as life expectancy goes from 48 to 68 and then to 77. Some facts are worthy of comment. As longevity increases, people enter later in the labor market (as seen in Figure 1). They also work less hours during the period of their life when productivity is increasing, as the graphs shift down continuously. This is due to the income effect caused by higher education and wages and the normality of leisure. Finally, people stay longer in the labor market. 


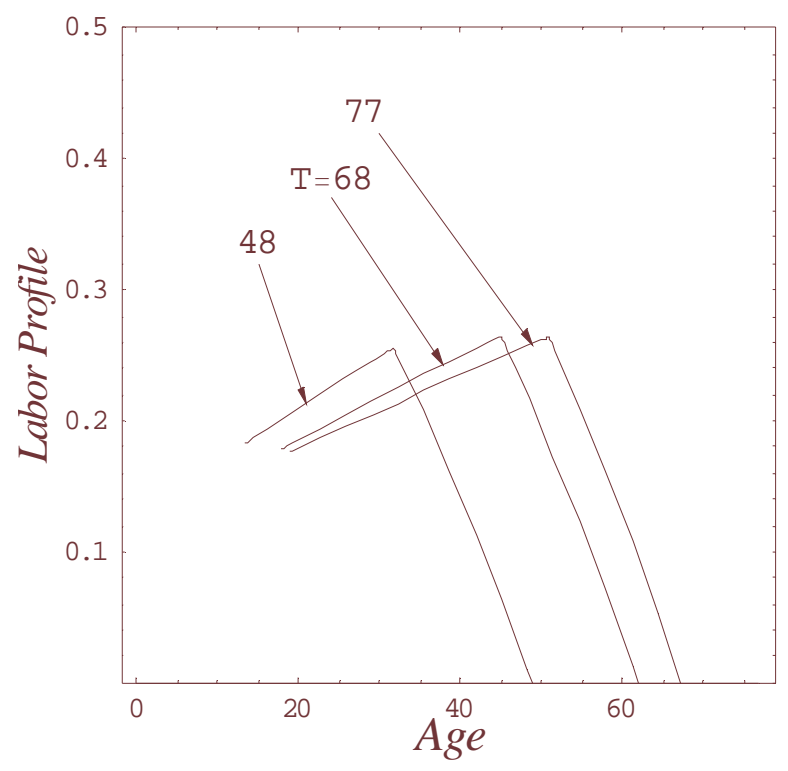

Figure 2: Life cycle labor profiles with different longevities

One caveat is that, although we were able to obtain increasing retirement life throughout the years as in the data, we are not able to reproduce the evidence that retirement age has been falling in the recent past. We do not consider this a serious problem as the simulated figures are close to constant for the last few years. For instance, retirement age was estimated to be 67.2 years of age in 2000, 66.3 in 1990, 65.4 in 1980 and 63.5 in 1970.

Nonetheless, the observed fact is that on average individuals are retiring earlier in life over the last decades, and we do not capture this perfectly. One possible solution is to change across years the learning coefficients $\gamma$ and $\zeta$. This is not arbitrary because the estimated dummies are not the same across decades. For instance, the estimated productivity profile in 1940 is below that of 1990 for its entire positive portion. In this case $\gamma$ could be larger in 1990 than in 1940, so that people would work more intensively in the first part of their productive life, increase savings and retire earlier. Figure 3 shows two labor profiles, one obtained from the benchmark calibration $(\gamma=1.25 \%)$ and one using gamma equal to $2.0 \%$. 


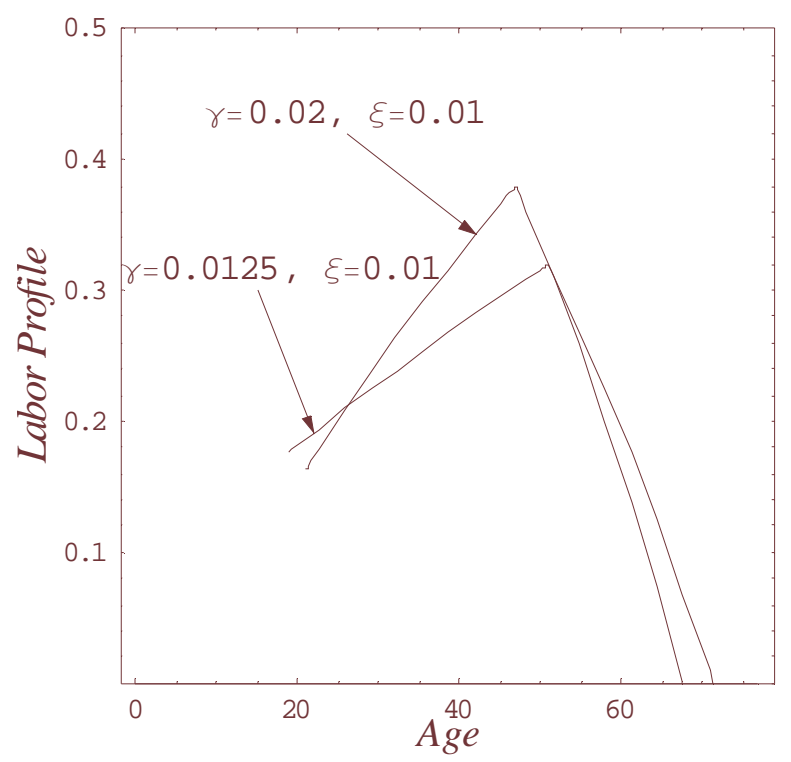

Figure 3: Life cycle labor profiles with different learning rates

If the productivity growth rate (i.e., gamma) in the first period of working life rises, individuals will work more intensively during most of their active life and then retire earlier. This is so because the opportunity cost of leisure in the earlier years of working life increases with respect to that of old age.

Note also that individuals enter later in the job market, acquiring more education. This means that, in essence, what matters for schooling is not the extension of productivity life, but its intensity. In models such as Soares(2003) and Kalemhi-Ozcan and Weil (2000), longer life allows for longer productivity life, raising the return to human-capital investment and so to education. One problem here is that, especially in rich capitalist economies, increases in life expectancy were followed by more than proportional increases in retirement, in which case this result does not hold. However, if for some reason the productivity growth rate due to experience jumps up, the return to education investment also increases, so people will want to acquire more of it even if longevity does not change. If this jump is high enough, the extension of productivity life - i.e., time in the labor market - may well decrease as in Figure $3^{12}$.

\footnotetext{
${ }^{12}$ Note, however, that the evidence is not clear that $\gamma$ increased monotonically in all the previous decades.
} 
Table 1 below resumes some of the above results while also presenting the impact of longevity changes on income, keeping all other parameters constant.

Table 1: Long-Run Impact of

\begin{tabular}{ccccc}
\multicolumn{5}{c}{ Longevity } \\
\hline$T$ & $T_{S}$ & $y$ & $T_{R}$ & Retirement \\
77 & 13 & 1 & 67.22 & 9.78 \\
70 & 12.1 & 0.92 & 63.10 & 6.90 \\
65 & 11.2 & 0.86 & 60.10 & 4.90 \\
60 & 10.4 & 0.80 & 57.05 & 2.95 \\
55 & 9.4 & 0.73 & 53.95 & 1.05 \\
50 & 8.0 & 0.63 & 50.00 & 0 \\
\hline
\end{tabular}

As one could expect, per capita income decreases with longevity. For instance, when $T=60$, estimated income per capita is $80 \%$ of that of the benchmark model. One possible interpretation is that a country with everything else equal to the U.S. but longevity would be $20 \%$ poorer if its life expectancy was 17 years smaller. Some of the channels are displayed in the table (smaller education and earlier retirement). How relevant is this? In 1997, life expectancy in Bolivia was 61 years and its income relative to the U.S. was $9 \%$. Hence, there is still a very large income difference left unexplained. This is not surprising, given that there are many other dimensions were these economies can differ that we hold constant, such as productivity ${ }^{13}$.

As already commented on, retirement life increases more than proportionally with longevity, reproducing the evidence: when $T$ is 77 the model predicts that an individual will spend $13 \%$ of his life in retirement, but only $1 \%$ when $T$ is 55 and he will die before retirement if longevity is smaller than 52 years.

In any case, what matters is the relative growth rate at different ages, and the evidence is very strong that experience gains in old age have been falling much faster in recent years.

${ }^{13}$ Results concerning productivity differences are as expected. An economy equal in every aspect to the US but with only $80 \%$ of its total- factor productivity would have only $70 \%$ of the income per capita of the latter. The impact is mostly felt through physical capital, as education and retirement almost do not change with $A_{1}$. 


\section{Distortions, Education and Income}

Up to this point we have kept distortions constant while allowing longevity to vary. We have seen that changes in life expectancy have significant impacts on life-cycle decisions such as education and retirement and also on income per capita. In this section we study the sensitivity of the model to modifications in the three distortion parameters.

As the model includes life-cycle features, saving and labor decisions and two sectors of production, its general equilibrium structure incorporates different transmission mechanisms, and is a rich environment to study the relative impact of different forms of taxation. Remember that in this economy the government imposes taxes on labor income, capital income and the direct cost of education. It is not clear which of these has a stronger impact on education and income. For instance, tax on physical-capital returns imposes the usual distortions on saving decisions, investment and capital stock. The latter affects the marginal productivity of labor - and so the labor and education decision - and the production of education services, which uses capital. Tax on labor, in it turn, directly affects the labor and leisure decision. It also affects the education and retirement decision, and so working life and the long-run return on physical and human capital.

The picture below presents life cycle labor profiles for $\tau_{L}$ equal to $0.2,0.4$ and 0.6. Note that the graphs shift down as $\tau_{L}$ increases, so that, similarly to the standard neoclassical model, higher taxes on labor income lead to less hours worked. There however are, two additional effects: individuals will enter and leave the labor market earlier. In the first case because more taxes on labor reduces the return to human-capital investment, so schooling decreases. In the second case because the relative cost of leisure - and retirement too decreases. This a significant amplification of the effect of labor taxation on the economy that is not captured in standard neoclassical models. Moreover, as labor supply decreases, physical capital also falls in equilibrium, as its marginal product is now smaller. 


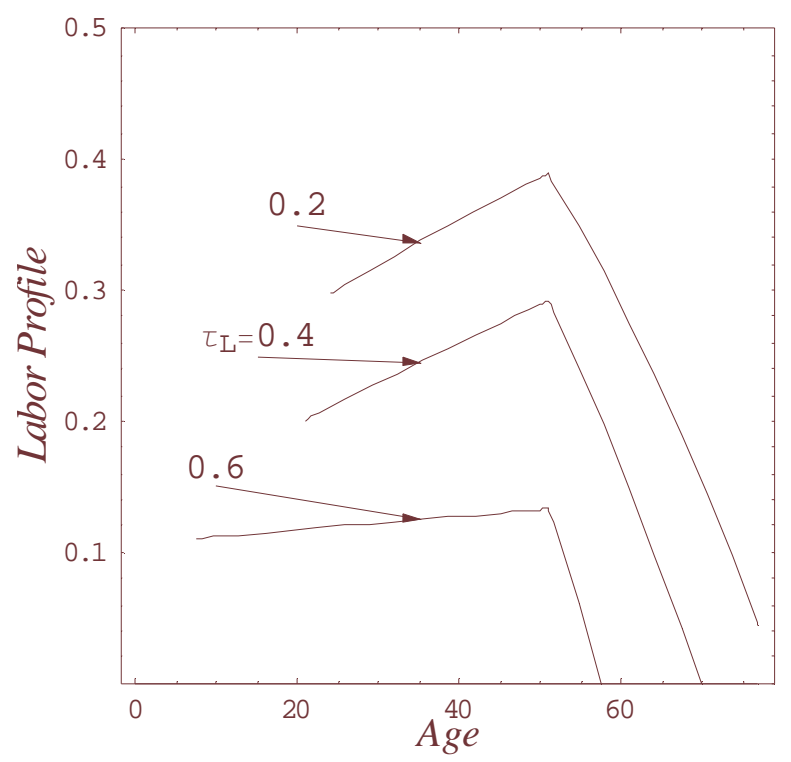

Figure 4: Life cycle labor profiles for different labor taxes

Table 2 below presents the results of an exercise in which $\tau_{L}$ varies and everything else is kept constant at the benchmark values, similar to the picture above:.

Table 2: Long-Run Impact of

\begin{tabular}{cccc}
\multicolumn{4}{c}{ Labor Taxation } \\
\hline$\tau_{L}$ & $T_{S}$ & $y$ & $T_{R}$ \\
0.45 & 13 & 1 & 67.22 \\
0.0 & 18.3 & 1.93 & 77 \\
0.2 & 18.2 & 1.85 & 77 \\
0.4 & 14.9 & 1.23 & 69.8 \\
0.6 & 1.53 & 0.19 & 57.5 \\
\hline
\end{tabular}

As said before, income in the benchmark economy - the U.S. in the present - is set equal to one and the estimated tax rate was found to be 0.45 , as seen in the first line. In addition to the direct impact on labor supply displayed in Figure 4, reductions in $\tau_{L}$ increase education, retirement age and capital (not shown). For instance, in an economy in which 
the tax rate is 0.20 , close to half the U.S. figure, the model predicts that individuals will stay five additional years in the educational system and not retire before dying, although at this moment the labor effort will be considerably smaller than in the peak years. The influence of labor taxation on retirement reinforces the impact on per capita income, wich in this case $\left(\tau_{L}=0.20\right)$ will be 85 percent larger. In contrast, if labor taxes were higher and equal to 0.60 , income per capita would be only $20 \%$ of the American income, and education close to one tenth. This seems a bit strong, but it indicates that labor taxation has enough potential to explain differences in standards of living (and educational levels) across economies.

Pictures similar to Figure 4 apply to the cases of $\tau_{H}$ and $\tau_{K}$. (see the appendix). Table 3 below presents retirement age, per capita income and education levels corresponding to different values of $\tau_{H}$. The first line, once again, corresponds to the benchmark case.

\begin{tabular}{cccc}
\multicolumn{4}{c}{ Table 3} \\
\multicolumn{4}{c}{ Long-Run Impact of } \\
\hline$\tau_{H}$ & $y$ & $T_{s}$ & $T_{R}$ \\
0.02 & 1 & 13 & 67.22 \\
0.20 & 0.85 & 10.46 & 66.52 \\
0.40 & 0.38 & 3.02 & 62.75 \\
0.6 & 0.20 & 0.65 & 59.69 \\
\hline
\end{tabular}

Taxes on educational services have a significant impact on this economy. An economy equal to the U.S. in everything but $\tau_{H}$ equal to 0.2 instead of the benchmark value of 0.02 , would be $15 \%$ poorer and would have 2.5 years less schooling.

Figure 5 below compares the relative impact on income per capita of the different types of taxes, when we hold other parameters (and the two remaining taxes) constant at their calibrated values. 


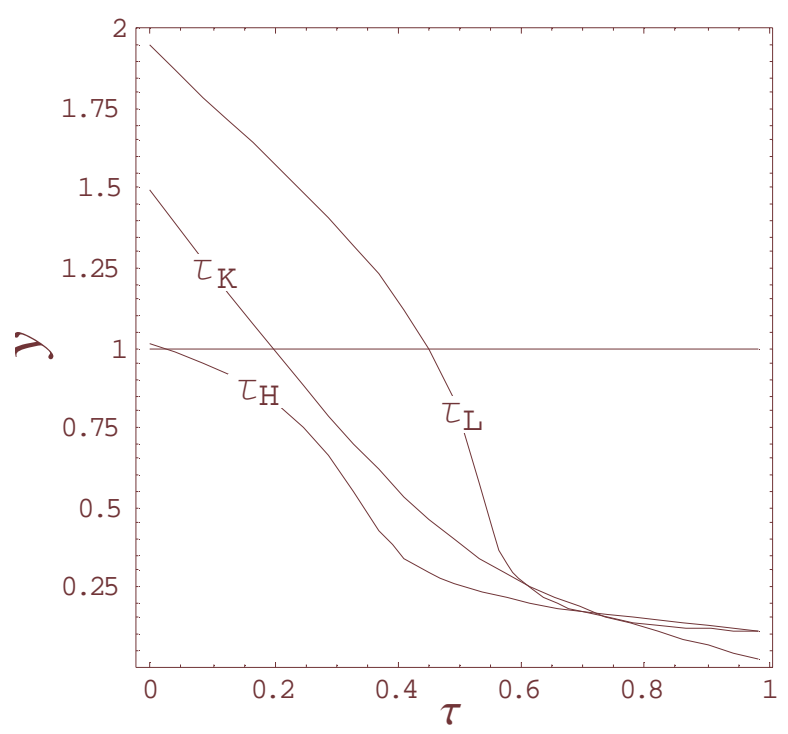

Figure 5:the impact of the different types of taxes on income

Note that the three lines almost intersect around 0.72, so that income per capita implied by this level of taxation will be the same whether we consider $\tau_{H}, \tau_{K}$ or $\tau_{L}$. As we decrease the level of tax rates, we notice that the simulated effect of labor taxation on long-run income is greater, followed by that of $\tau_{K}$, which, in turn is stronger than that of $\tau_{H}$.

The dominant impact of labor taxation is at first thought, surprising and is a feature of the life-cycle structure of the model. Note that distortions to the accumulation of physical capital have a direct effect on both sectors and an indirect effect on the returns to educational investment. In most studies on public finance, capital taxation is more detrimental to the economy than labor taxation.

In this economy this is not the case, in the first place because, as we can see from Figure 4 , decreases in $\tau_{L}$ shifts up the life-cycle labor profile and it is straightforward to verify that the impact here is stronger than in the case of $\tau_{K}$ and $\tau_{H}$. Moreover, individuals will retire later or not retire at all if labor taxation is too small, something that we do not verify with other forms of taxation. In the case of direct tax on tuition, this effect is relatively small. Finally, reductions in labor taxation raise the return to human capital investment leading to higher schooling levels. At higher levels of labor taxation individuals acquire almost no education, which is not true for capital taxation. 


\section{Conclusion}

In this paper we have studied a finite life economy in which higher life expectancy explains increases in schooling and retirement and plays an important role in the determination of long-run income. This role could only appear because of the hypothesis of finite life and the Mincerian formulation of human capital, which seem to us the most realistic assumptions. When calibrated to the U.S. experience during last century we reproduced education levels and showed that a $20 \%$ difference in longevity, everything else being constant, would lead to a $15 \%$ gap in per capita income.

The mechanism of the model that allows for retirement, in addition to the labor-leisure choice, is an experience profile that mimics the parabolic shape estimated by studies in the labor field. As productivity decreases or slows down at old age, at a certain point in life the marginal gain of working is below that of leisure, and people leave the job market. Longer lives allow people to enjoy proportionally larger retirement. If, on top of that, the productivity profile jumps up so that young people learn relatively faster, we obtain that the retirement age falls, replicating the evidence.

The sensitivity analysis and tax simulations showed that life-cycle aspects are very important to the study of public policy and the allocative effect of taxation. Once schooling and retirement decisions are incorporated to the analysis, and career span being finite, laborcapital taxation and, to a lesser extent, human-capital taxation have significant effects on the long-run level of per capita income and variables such as labor supply, retirement and physical-capital investment. The literature on physical-capital taxation, however, is much more extensive than that on human-capital taxation, although there are important exceptions, most of them using endogenous growth models. One possible reason is that in many models taxation on human capital is neutral, as it decreases not only its return but also reduces the cost of being out of the labor market. However, our results show that if there are any other costs imposed on the acquisition of education which are not proportional to wages (e.g., tuition), the long-run impact of any form of taxation on human capital - either direct on tuition or indirect on wages - is relevant. 


\section{.1 Appendix 1: Factor-allocation problem}

In this economy there is free mobility of factors across sectors, so that factors price are the same in both sectors. Considering the good 1 as the numeraire, it follows that:

$$
R \equiv R_{1}=\alpha_{1} A_{1} k_{1}^{\alpha_{1}-1}=p \alpha_{2} A_{2} k_{2}^{\alpha_{2}-1}=R_{2}
$$

and

$$
w \equiv w_{1}=\left(1-\alpha_{1}\right) A_{1} k_{1}^{\alpha_{1}}=p\left(1-\alpha_{2}\right) A_{2} k_{2}^{\alpha_{2}}=w_{2},
$$

where $p$ is the relative price of educational services in units of goods. Dividing the second equation by the first we obtain the wage-rental ratio as a function of the capital-labor ratio in the $i$-th sector:

$$
\omega \equiv \frac{w}{R}=\frac{1-\alpha_{i}}{\alpha_{i}} k_{i}
$$

In order to express the relative price of final goods as a function of the relative price of production factors we employ the zero-profit condition to obtain,. after some simplifications:

$$
p=\frac{A_{1} k_{1}^{\alpha_{1}-1}}{A_{2} k_{2}^{\alpha_{2}-1}} \frac{\alpha_{1}}{\alpha_{2}} .
$$

If again we substitute (19) into this last equation we can express the relative price of factors as a function of the relative price of goods:

$$
\omega=\left(\frac{A_{2}}{A_{1}} \frac{\alpha_{2}^{\alpha_{2}}}{\alpha_{1}^{\alpha_{1}}} \frac{\left(1-\alpha_{2}\right)^{1-\alpha_{2}}}{\left(1-\alpha_{1}\right)^{1-\alpha_{1}}} \cdot p\right)^{\frac{1}{\alpha_{1}-\alpha_{2}}},
$$

From (19) and (20) follows the optimum capital-labor ratio as a function of the relative price of the final goods:

$$
k_{i}=\frac{\alpha_{i}}{1-\alpha_{i}}\left(\frac{A_{2}}{A_{1}} \frac{\alpha_{2}^{\alpha_{2}}}{\alpha_{1}^{\alpha_{1}}} \frac{\left(1-\alpha_{2}\right)^{1-\alpha_{2}}}{\left(1-\alpha_{1}\right)^{1-\alpha_{1}}} p\right)^{\frac{1}{\alpha_{1}-\alpha_{2}}} .
$$

To wrap up the factor-allocation problem we have to find the scale of production of each sector. Let $l_{i}$ be the share of the labor force in the $i$-th sector, $l$ the (per capita) total flow of labor services and $k$ the (per capita) endowment of capital. Full employment of labor and capital services implies:

$$
\begin{aligned}
l_{1} k_{1}+l_{2} k_{2} & =k \\
l_{1}+l_{2} & =1
\end{aligned}
$$


where $k \equiv \frac{K}{l e^{n t} e^{\phi\left(T_{\mathrm{S}}\right)}}$ is the per-worker capital stock in efficiency units. These last two equations solve for $l_{i}$ as a function of $k_{i}$ and $k$.

At a point in time, given $k$ and $p$ we get the offer function of each sector as follows:

$$
y_{i}(p, k)=A_{i} l e^{\phi\left(T_{\mathrm{S}}\right)} l_{i}(p, k)\left[k_{i}(p)\right]^{\alpha_{i}}, \quad i=1,2
$$

where $k_{i}(p)$ is given by (21), $y_{i} \equiv \frac{Y_{i}}{e^{n t}}$ is the per capita supply functions, $e^{n t}$ is total population and:

$$
l_{1}(p, k)=\frac{k_{2}(p)-k}{k_{2}(p)-k_{1}(p)}, \text { and } l_{2}(p, k)=\frac{k-k_{1}(p)}{k_{2}(p)-k_{1}(p)}
$$

It will be useful for the calibration to solve the model (under the assumption of full employment of factors) for $k_{1}$ and $k_{2}$ :

$$
k_{1}=\frac{\frac{\alpha_{1}}{1-\alpha_{1}}}{\frac{\alpha_{1}}{1-\alpha_{1}} l_{1}+\frac{\alpha_{2}}{1-\alpha_{2}} l_{2}} \widetilde{k} \text { and } k_{2}=\frac{\frac{\alpha_{2}}{1-\alpha_{2}}}{\frac{\alpha_{1}}{1-\alpha_{1}} l_{1}+\frac{\alpha_{2}}{1-\alpha_{2}} l_{2}} \widetilde{k}
$$




\section{.2 Appendix 2: Additional Tables and Figures}

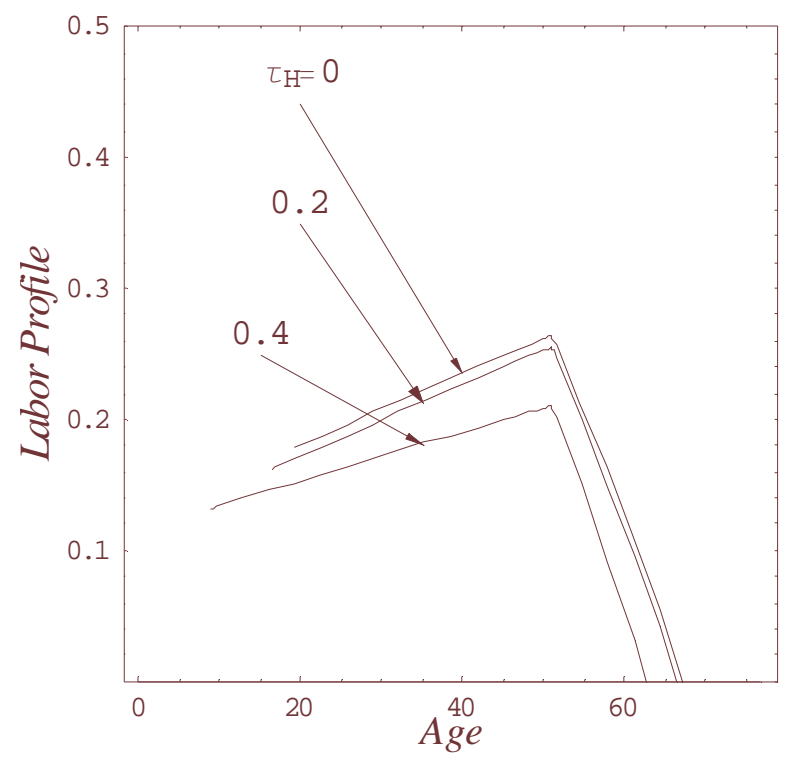

Figure A.1: Life-cycle labor profiles for different tax rates on education

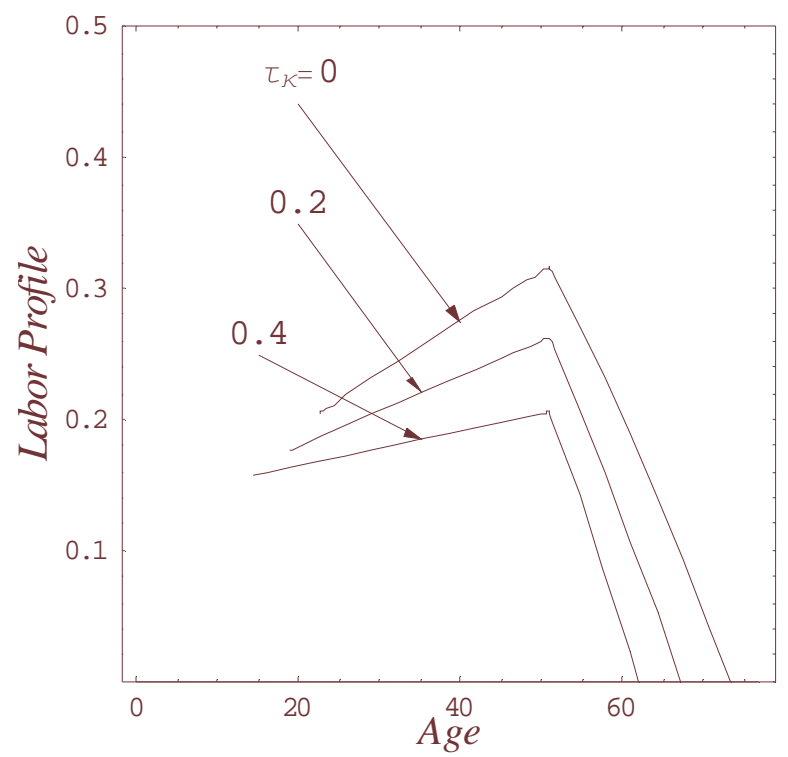

Figure A.2: Life-cycle labor profiles for different tax rates on capital 
Table A1: Long-Run Impact of

\begin{tabular}{cccc}
\multicolumn{4}{c}{ Physical Capital Taxation } \\
\hline$\tau_{K}$ & $y$ & $T_{s}$ & $T_{R}$ \\
0.2 & 1 & 13 & 67.22 \\
0.0 & 1.67 & 16.61 & 73.32 \\
0.40 & 0.50 & 8.37 & 62.01 \\
0.60 & 0.21 & 4.21 & 57.66 \\
\hline
\end{tabular}

\section{References}

[1] Bills, M. and P. Klenow 2000. "Does Schooling Cause Growth?," American Economic Review, 90(5): 1160-1183.

[2] Boucekkine, R; D. de la Croix and O. Licandro, 2002, "Vintage human capital, demographic trends and endogenous growth," Journal of Economic Theory, 104, 340375

[3] Boucekkine, R; D. de la Croix and O. Licandro, 2003, "Early Mortality Declines at the Dawn of Modern Growth", Scandinavian Journal of Economics, 105, 401-418.

[4] Enrlich, I. and F. Lui, 1991, "Intergenerational Trade, Longevity, Intrafamily Transfers and Economic Growth," Journal of Political Economy, 99(5), 1029-1059.

[5] Folger, J.K. and C.B. Nam "Educational Trends from Census Data", Demography, vol. 1, 247-257.

[6] Gendell, M. and J. Siegel, 1992, "Trends in Retirement Age by Sex, 1950-2005," Monthly Labor Review, July, 22-29.

[7] Graebner, W.,1980. "A History of Retirement: The Meaning and Function of an American Institution, 1885-1978, New Haven, CO: Yale University Press.

[8] Gustavus, S O. and C.B. Nam, 1968, "Estimates of the 'True' Educational Distribution of the Adult Population of the United States from 1910 to 1960", Demography, vol. $5, \mathrm{n}^{\circ} 1,410-421$ 
[9] Heckman, J., L. Lochner e P. Todd, 2003, Fifty Years of Mincer Earnings Regressions, Mimeo, Chicago University.

[10] Hendricks, L. 1999. "Taxation and Long-Run Growth," Journal of Monetary Economics 43: 411-434.

[11] Jones. C., 2002 "Sources of U.S. Economic Growth in a World of Ideas," American Economic Review, 92: 220-239.

[12] Kaboski,J.P., 2003, "Growth, Technology \& Inequality with Rising Schooling Attainment", manuscript, Ohio State University.

[13] Kalemli-Ozcan, S.; H.E.Ryder and D.N.Weil, 2000, "Mortality Decline, Human Capital Investment, and Economic Growth", Journal of Development Economics, vol. 62, 1-23.

[14] Kalemli-Ozcan, S. and D.N. Weil, 2004, "Mortality Change, the Uncertainty Effect, and Retirement", manuscript.

[15] Kirk, D.,1996, "Demographic Transition Theory", Population Studies, 50(3), 361-87.

[16] Krueger, A. B., Lindahl, M. 2000. "Education for Growth: Why and for Whom?" NBER Working Paper No. 7591, March.

[17] Lee, C., 2001. "The Expected Length of Male Retirement in the United States, 18591990," Journal of Population Economics, V.14, 641-650.

[18] Lee, R., 1980. "An Historical Perspective on Economic Aspects of the Population Explosion: the Case of Pre-industrial England", in Richard Easterlin, ed., Population and Economic Change in Developing Countries (University of Chicago Press).

[19] Lucas, Jr, R.E., 1990, "Supply-Side Economics: An Analytical Review", Oxford Economic Papers, New Series,vol.42, no 2, 293-316.

[20] Mateus-Planas, X. 2001. "Schooling and Distortion in a Vintage Capital Model," Review of Economic Dynamic 4: 127-158.

[21] McGrattan, E.R. and R.Rogerson, 1998, "Changes in Hours Worked Since 1950", Federal Reserve Bank of Minneapolis Quarterly Review, vol. 22, no 1, 2-19 
[22] National Vital Statistics Reports, 2002, National Center for Health Statistics.

[23] Prescott, E. 2004, "Why Do Americans Work So Much More Than Europeans?" Federal Reserve Bank of Minneapolis Quarterly Review, vol. 28, n 1, 2-13.

[24] Preston, S.H, 1975, "The Changing Relation between Mortality and Level of Economic Development", Population Studies, 29, 2., 231-248.

[25] Preston, S.H., 1977, "Mortality Trends", Annual Review of Sociology, 3, 163-78.

[26] Psacharopoulos, G. 1994. "Returns to Investment in Education: A Global Update," World Development, 22(9), 1325-1343.

[27] Soares, R., 2003, "Mortality Reductions, Educational Attainment, and Fertility Choice", manuscript, University of Maryland.

[28] Stokey, N. L., Rebelo, S. 1995. "Growth Effects of Flat-Rate Taxes," Journal of Political Economy 103(3): 519-550.

[29] Trostel, P. A. 1993. "The Effect of Taxation on Human Capital," Journal of Political Economy 101(2): 327-350. 


\section{Últimos Ensaios Econômicos da EPGE}

[565] Marcelo Casal de Xerez e Marcelo Côrtes Neri. Desenho de um sistema de metas sociais. Ensaios Econômicos da EPGE 565, EPGE-FGV, Set 2004.

[566] Paulo Klinger Monteiro, Rubens Penha Cysne, e Wilfredo Maldonado. Inflation and Income Inequality: A Shopping-Time Aproach (Forthcoming, Journal of Development Economics). Ensaios Econômicos da EPGE 566, EPGE-FGV, Set 2004.

[567] Rubens Penha Cysne. Solving the Non-Convexity Problem in Some ShoppingTime and Human-Capital Models. Ensaios Econômicos da EPGE 567, EPGEFGV, Set 2004.

[568] Paulo Klinger Monteiro. First-Price auction symmetric equlibria with a general distribution. Ensaios Econômicos da EPGE 568, EPGE-FGV, Set 2004.

[569] Samuel de Abreu Pessôa, Pedro Cavalcanti Gomes Ferreira, e Fernando A. Veloso. On The Tyranny of Numbers: East Asian Miracles in World Perspective. Ensaios Econômicos da EPGE 569, EPGE-FGV, Out 2004.

[570] Rubens Penha Cysne. On the Statistical Estimation of Diffusion Processes A Partial Survey (Revised Version, Forthcoming Brazilian Review of Econometrics). Ensaios Econômicos da EPGE 570, EPGE-FGV, Out 2004.

[571] Aloisio Pessoa de Araújo, Humberto Luiz Ataide Moreira, e Luciano I. de Castro Filho. Pure strategy equilibria of multidimensional and Non-monotonic auctions. Ensaios Econômicos da EPGE 571, EPGE-FGV, Nov 2004.

[572] Paulo César Coimbra Lisbôa e Rubens Penha Cysne. Imposto Inflacionário e Transferências Inflacionárias no Mercosul e nos Estados Unidos. Ensaios Econômicos da EPGE 572, EPGE-FGV, Nov 2004.

[573] Renato Galvão Flôres Junior. Os desafios da integração legal. Ensaios Econômicos da EPGE 573, EPGE-FGV, Dez 2004.

[574] Renato Galvão Flôres Junior e Gustavo M. de Athayde. Do Higher Moments Really Matter in Portfolio Choice?. Ensaios Econômicos da EPGE 574, EPGEFGV, Dez 2004.

[575] Renato Galvão Flôres Junior e Germán Calfat. The EU-Mercosul free trade agreement: Quantifying mutual gains. Ensaios Econômicos da EPGE 575, EPGE-FGV, Dez 2004.

[576] Renato Galvão Flôres Junior e Andrew W. Horowitz. Beyond indifferent players: On the existence of Prisoners Dilemmas in games with amicable and adversarial preferences. Ensaios Econômicos da EPGE 576, EPGE-FGV, Dez 2004. 
[577] Rubens Penha Cysne. Is There a Price Puzzle in Brazil? An Application of Bias-Corrected Bootstrap. Ensaios Econômicos da EPGE 577, EPGE-FGV, Dez 2004.

[578] Fernando de Holanda Barbosa, Elvia Mureb Sallum, e Alexandre Barros da Cunha. Competitive Equilibrium Hyperinflation under Rational Expectations. Ensaios Econômicos da EPGE 578, EPGE-FGV, Jan 2005.

[579] Rubens Penha Cysne. Public Debt Indexation and Denomination, The Case of Brazil: A Comment. Ensaios Econômicos da EPGE 579, EPGE-FGV, Mar 2005.

[580] Renato Galvão Flôres Junior, Germán Calfat, e Gina E. Acosta Rojas. Trade and Infrastructure: evidences from the Andean Community. Ensaios Econômicos da EPGE 580, EPGE-FGV, Mar 2005.

[581] Edmundo Maia de Oliveira Ribeiro e Fernando de Holanda Barbosa. A Demanda de Reservas Bancárias no Brasil. Ensaios Econômicos da EPGE 581, EPGEFGV, Mar 2005.

[582] Fernando de Holanda Barbosa. A Paridade do Poder de Compra: Existe um Quebra-Cabeça?. Ensaios Econômicos da EPGE 582, EPGE-FGV, Mar 2005.

[583] Fabio Araujo, João Victor Issler, e Marcelo Fernandes. Estimating the Stochastic Discount Factor without a Utility Function. Ensaios Econômicos da EPGE 583, EPGE-FGV, Mar 2005.

[584] Rubens Penha Cysne. What Happens After the Central Bank of Brazil Increases the Target Interbank Rate by 1\%?. Ensaios Econômicos da EPGE 584, EPGEFGV, Mar 2005.

[585] Gustavo Gonzaga, Naércio Menezes Filho, e Maria Cristina Trindade Terra. Trade Liberalization and the Evolution of Skill Earnings Differentials in Brazil. Ensaios Econômicos da EPGE 585, EPGE-FGV, Abr 2005.

[586] Rubens Penha Cysne. Equity-Premium Puzzle: Evidence From Brazilian Data. Ensaios Econômicos da EPGE 586, EPGE-FGV, Abr 2005.

[587] Luiz Renato Regis de Oliveira Lima e Andrei Simonassi. Dinâmica Não-Linear e Sustentabilidade da Dívida Pública Brasileira. Ensaios Econômicos da EPGE 587, EPGE-FGV, Abr 2005.

[588] Maria Cristina Trindade Terra e Ana Lucia Vahia de Abreu. Purchasing Power Parity: The Choice of Price Index. Ensaios Econômicos da EPGE 588, EPGEFGV, Abr 2005.

[589] Osmani Teixeira de Carvalho Guillén, João Victor Issler, e George Athanasopoulos. Forecasting Accuracy and Estimation Uncertainty using VAR Models with Short-and Long-Term Economic Restrictions: A Monte-Carlo Study. Ensaios Econômicos da EPGE 589, EPGE-FGV, Abr 2005. 